\title{
REAÇÕES DO MERCADO ACIONÁRIO FRENTE À REGULAÇÃO DA REMUNERAÇÃO DOS EXECUTIVOS: UMA INVESTIGAÇÃO SOBRE O SETOR BANCÁRIO NACIONAL E INTERNACIONAL LISTADO NA [B]3
}

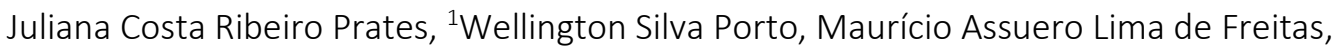 \\ Luiz Carlos Maques dos Anjos \\ Universidade Federal de Pernambuco - UFPE, Pernambuco, (Brasil)
}

\section{DETALHES DO ARTIGO \\ Histórico do Artigo: \\ Recebido em: 04 de Maio de 2020 \\ Aceito: 07 de Julho de 2021 \\ Disponível online: 01 de Setembro de 2021}

Sistema de revisão "Double blind review"

\section{Editor Científico}

Ilan Avrichir

\section{Palavras-chaves:}

Remuneração de Executivos

Regulação

Quebra Estrutural

VAR

Estudo de Eventos

\section{RESUMO}

Objetivo: Compreender como os shareholders do setor bancário da B3 tiveram seus investimentos impactados frente à introdução da obrigatoriedade da divulgação da remuneração dos executivos no Brasil, em decorrência da publicação da IN CVM 480/2009.

Método: Para o desenvolvimento da pesquisa foi feita uma análise de comparação de médias condicionais com o uso de vetores autorregressivos (VAR), para identificação da quebra estrutural e da metodologia de estudo de eventos.

Principais resultados: Os resultados mostram que houve quebra estrutural da média de retorno acionário assim como da taxa de crescimento da remuneração média dos executivos, apresentando impacto negativo no período posterior à regulação. $O$ impacto negativo advindo da regulação foi captado pelo modelo no mês seguinte à publicação da IN CVM 480/2009 e nos 3 dias após a regulação.

Relevância/Originalidade: Os resultados são importantes aos reguladores e demais participantes do mercado, pois indicam a mudança na percepção dos participantes do mercado a partir da regulação, mostrando que a regulação pode modificar os contratos de compensação dos executivos e assim, promover o alinhamento de interesses dentro do setor financeiro.

Contribuições teóricas/metodológicas: O estudo contribui para o entendimento dos efeitos da regulação na remuneração dos executivos do setor financeiro brasileiro. Além disso, contribui para a literatura ao estimular o debate acerca das especificidades do setor bancário brasileiro sobre o desenvolvimento de mecanismos de governança corporativa voltados ao setor, como forma de mitigar a tomada de riscos que tende a comprometer toda a economia do país. Os resultados também são importantes aos reguladores, na medida em que sugerem que a regulação foi benéfica na redução do conflito de interesses entre agente e principal. Além disso, a contribuição metodológica consiste em utilizar-se o modelo VAR (Vetores Autorregressivos) paralelamente ao estudo de eventos, reforçando a originalidade da pesquisa e promovendo melhor aprofundamento dessa temática.

\section{INTRODUÇÃO}

A regulação concernente à divulgação da remuneração dos executivos das empresas que operam no mercado de capitais, teve início nos
Estados Unidos da América (EUA), em 1938 (Murphy, 1999). O intuito dessa regulação foi reduzir informações assimétricas e, consequentemente, problemas de agência. A United States Securities and Exchange Commission (SEC) desenvolveu o conteúdo 
e a forma de divulgação dessa norma regulatória e, por décadas os Estados Unidos permaneceram sozinhos nessa tentativa, mas os efeitos dessa regulação foram percebidos no aumento do tamanho das remunerações dos seus executivos que, segundo Murphy (2013), possui os Chief Executive Officers (CEOs) mais bem pagos do mundo.

Em contrapartida, no Brasil, somente a partir do ano de 2009 com a Instrução Normativa nㅇ 480, de 7 de dezembro do mesmo ano (IN CVM 480/2009), publicada pela Comissão de Valores Mobiliários (CVM), as empresas passaram a ter obrigatoriedade de evidenciação da remuneração dos executivos. A regulação sobre os rendimentos desses executivos tenderia a limitar o grau de risco ao qual o gestor da instituição seria capaz de submetê-la (Murphy, 2013; De Angelis, \& Grinstein, 2014; Zalewska, 2016), fato que beneficiaria as economias em situações de crise, como a enfrentada em 2008, cujos governos seriam obrigados a socorrer as instituições financeiras em nome de pequenos poupadores e correntistas, prejudicados com o possível comportamento oportunista dos executivos, que apenas visavam maiores lucros imediatos com o propósito de aumentar suas remunerações (Conyon, Fernandes, Ferreira, Matos, \& Murphy, 2011).

Sob a ótica teórica, a regulação é uma inovação social que surge em momentos de dificuldades com a livre negociação e atuação dos mercados. Na maioria das vezes, a regulação interessa à sociedade e não às empresas, que deverão observá-la e adequar-se aos seus preceitos, visto que se trata de externalidades que podem, em geral, representar a incorrência de maiores custos, afetando lucros e dividendos. Do ponto de vista das empresas do mercado financeiro a regulação tornou o ambiente mais complexo, evitando inovações financeiras que pudessem representar risco aos investidores de boa-fé.

Dessa forma, é relevante elucidar o seguinte questionamento: Como se comportou o retorno das ações das instituições financeiras listadas na B3 frente à regulação da remuneração dos executivos? A principal justificativa para tal investigação é a representatividade do setor bancário listado na B3, que no ano de 2016 chegava a 83\% do ativo total do Sistema Financeiro Nacional (SFN), concentrado em apenas cinco bancos, o que representa risco importante à economia.

O objetivo do estudo é, portanto, compreender como os shareholders do setor bancário da B3 tiveram seus investimentos impactados em decorrência da publicação da IN CVM 480/2009, avaliando seu comportamento pré e pós regulação, a partir de uma série histórica cuja variável resposta é o valor da firma mensurado pelo valor de suas ações no mercado.

Este estudo faz uso de um modelo autoregressivo VAR com dados trimestrais e da metodologia de estudo de eventos com dados diários, como análise de robustez. A pesquisa procura identificar sinais de uma mudança estrutural significativa para o valor das ações, que justifique o comportamento desses preços após a regulação da remuneração dos executivos.

As contribuições para a literatura, trazidas pela presente pesquisa, estimulam o debate acerca das especificidades do setor bancário brasileiro, considerando empresas nacionais e internacionais que negociam no mercado acionário nacional, sobre o desenvolvimento de mecanismos de governança corporativa voltados ao setor, como forma de mitigar a tomada de riscos que tendem a comprometer toda a economia do país. Os resultados também são importantes aos reguladores, na medida em que sugerem que a regulação foi benéfica na redução do conflito de interesses entre agente e principal.

O artigo está dividido em três seções, além desta introdução. A primeira faz um apanhado da literatura e referencial teórico sobre conflitos de agência, remuneração de executivos, governança corporativa e regulação. A segunda seção descreve a metodologia empregada para os dados coletados e analisados. Na terceira seção, avaliam-se esses resultados à luz das teorias e dos impactos específicos causados ao mercado. A quarta seção conclui.

\section{REFERENCIAL TEÓRICO}

A crise financeira de 2008 provocou uma onda de reestruturação da regulação em muitos países, em virtude de que essas antigas normas não foram capazes de evitar bolhas especulativas e trouxe à tona a necessidade de se investigar, de forma mais aprofundada, as instituições financeiras (Conyon et al. 2011; Murphy, 2013). Assim, em uma reação imediata à crise e à percepção do papel dos contratos de compensação orientados para o desempenho a curto prazo, a CVM instituiu a IN CVM 480/2009 que exige a divulgação anual da remuneração mínima, média e máxima dos executivos. 
Zalewska (2016) enfatiza que há um gap na literatura e também na regulação, tanto em relação à composição dos pacotes de remuneração de executivos em bancos, como em sua estruturação. Anjos (2016) argumenta que a principal motivação da intervenção regulatória em 2009 foi, além do cenário de crise econômica internacional, o surgimento de normas contábeis referentes ao reconhecimento, mensuração e evidenciação de aspectos inerentes a pagamentos de benefícios a empregados. Para Edmans, Gabaix e Jenter (2017) a obrigatoriedade de maior divulgação de pagamentos visa manter o poder dos acionistas, pois, através dessas informações, os acionistas podem decidir se o contrato atual é ótimo e modificá-lo, caso seja conveniente. Outro argumento que Edmans et al. (2017) apontam é o fato de tais divulgações possibilitarem a identificação e constrangimento de empresas que adotam uma compensação abaixo do ideal.

Segundo o Instituto Brasileiro de Governança Corporativa (IBGC) (2015), a regulação visa também proporcionar maior transparência às informações relativas à remuneração dos administradores de companhias listadas no Novo Mercado e beneficiar os interesses de investidores e correntistas, além de melhorar o processo de tomada de decisão de investimentos sobre a adequação de desempenho da administração das companhias e sua remuneração.

Dessa forma, a expectativa é que a divulgação de dados da remuneração dos executivos ocasione alinhamento entre interesses de administradores, acionistas e stakeholders, gerando redução de custos oriundos dos problemas de agência e, consequentemente, otimizando o desempenho da companhia, como já demonstrado em diversas pesquisas (Conyon, 1997; Garay, González, Guzmán, \& Trujillo, 2013; Murcia \& Machado, 2014; Scott \& O’Brien, 2019; Merchant \& Stede, 2017).

Apesar da CVM não pedir a abertura individual dos valores pagos caracterizados por executivo, houve uma decisão judicial que acolheu a tese de violação de intimidade e privacidade, fato que retardou as divulgações de tais informações. Por um lado, a Associação Brasileira das Companhias Abertas (ABRASCA) justificou um pedido de postergação por um ano para adoção da medida, alegando que a divulgação dos dados de remuneração demandaria significativos esforços de adaptação por parte das companhias abertas, principalmente no que diz respeito às políticas de recursos humanos e de segurança dos administradores. Por outro lado, diversas companhias listadas já haviam divulgado os dados em questão.

\subsection{Teoria de Agência e Remuneração}

Do ponto de vista da relação empresa-gestor, embora respaldada em contratos ou entendimentos mútuos entre indivíduos ou grupo de indivíduos que podem ser formais ou não, os indivíduos buscam alcançar seu próprio interesse, o que pode induzir tanto ao conflito quanto à cooperação (Coase, 1937; Sunder, 2014).

Nesse sentido e considerando a existência de assimetria da informação no mercado de trabalho (Akerlof, 1970; Oliveira \& Abrita, 2016), quando o agente busca maximizar seus próprios interesses em detrimento dos interesses do principal, surge o problema de agência (Jensen \& Meckling, 1976; Murphy, 1999; Conyon, 2006; Scott \& O'Brien, 2019).

A busca por uma forma de monitorar e controlar o comportamento dos agentes, motiva o principal a buscar meios de garantir que as ações tomadas pelos agentes estejam em conformidade com os seus interesses. A delegação de poder ao agente, por parte do principal, tanto para lutar por seus interesses quanto para tomada de decisões, cria um ambiente de incerteza em razão dos interesses específicos de cada grupo (Jensen \& Meckling, 1976). Tais interesses podem ou não ser convergentes e assim, visando alinhamento de ideias e valores dentro da organização, busca-se através de pacotes de incentivos aos executivos, reduzir a assimetria de informação.

No âmbito da equalização do problema, os acordos contratuais são tidos como uma solução eficiente para mitigar problemas de agência. As características contratuais como bônus vinculados ao desempenho da empresa, ou planos de opções de compra de ações, se relacionam com a teoria do agente-principal, de que os contratos de remuneração devem alinhar os interesses dos executivos com o objetivo do proprietário, ou seja a maximização de valor para os acionistas (Jensen \& Meckling, 1976; Aguiar \& Pimentel, 2017).

Porém, o poder gerencial propõe que os contratos observáveis não representem resultados eficientes, mas sirvam como veículos para que gestores poderosos extraiam compensação inadequada. Sob 
este ponto de vista, a remuneração dos executivos é vista não apenas como um instrumento potencial para abordar o problema de agência, mas também como parte do próprio problema de agência (Bebchuk \& Fried, 2003; Zalewska, 2016).

Assim, os mecanismos de controle ineficientes permitem aos gestores obter renda através de meios como: excesso de benefícios, uso estratégico de compensação ou opções de ações não suficientemente ligadas ao desempenho gerencial. Os contratos de remuneração são parte das escolhas de governança corporativa, porém, dadas as particularidades que moldam as escolhas de governança em nível de empresa, o grau de eficiência dos contratos de compensação não é observável. Há choques exógenos ao sistema de governança, que abalam os arranjos contratuais existentes, e que produzem insights reveladores (Frydman \& Jenter, 2010; Larcker, Ormazabal, \& Taylor, 2011; Hitz; Müller-Bloch, 2015).

Nesse sentido, Merchant e Stede (2017) tratam as práticas de governança corporativa como um mecanismo para gerar mais valor para os acionistas e nessa lógica, empresas com melhores práticas de governança corporativa estariam melhor satisfazendo os interesses de seus acionistas e stakeholders.

\subsubsection{Remuneração de Executivos no Brasil}

O IBGC propõe práticas visando maior transparência nas organizações, com o intuito de minimizar os conflitos e custos de agência. Uma destas práticas seria a definição de uma política de remuneração de executivos que represente, apropriadamente, os objetivos de curto e de longo prazo da organização, garantindo o cumprimento de seus planos estratégicos (IBGC, 2015). De forma similar, a CVM, através das Deliberações no 562/2008, 600/2009 e da IN CVM 480/2009, aprovou a obrigatoriedade de evidenciação de informações acerca da remuneração de executivos, como forma de possibilitar ao mercado a avaliação do desempenho organizacional com a remuneração paga aos executivos (Anjos, 2016).

O Banco Central do Brasil através da Resolução 3.921/2010 também deliberou a obrigatoriedade da política de remuneração de administradores das instituições financeiras, com ênfase na tomada de riscos dessas instituições e buscando minimizar conflitos de interesse. Segundo autores como Scott e O'Brien (2019) e Merchant e Stede (2017), a remuneração é um dos principais mecanismos de incentivo para os administradores, tanto para atrair gestores desejados como para avaliação do desempenho desses gestores, através dos resultados financeiros decorrentes de sua gestão. Assim, fica caracterizado o interesse público em ter acesso a esses dados.

A relação entre o desempenho da empresa e a remuneração de executivos está intrinsecamente ligada à evolução do preço das ações (Shah, Javed, \& Abbas, 2009), e sendo assim, Ventura (2013) enfatiza que os acionistas interessados na valorização de preços das ações e no alcance de metas empresariais de desempenho, contribuem direta ou indiretamente para que seus objetivos sejam interessantes, tanto para a empresa, como para seus executivos. A remuneração executiva, no contexto da Governança Corporativa, pode, portanto, ser analisada como um mecanismo de incentivo.

Sabe-se, porém, que contratos de incentivos robustos, com base em desempenho organizacional, criam oportunidades de manipulação de resultados, por exemplo, com o objetivo de aumentar os benefícios e remuneração dos gestores. Shleifer e Vishny (1997) e Bebchuck e Fried (2003) afirmam que os pacotes de remuneração de executivos nos EUA prejudicam seus acionistas, tendo em vista que seus incentivos falham na integração de interesses entre agente e principal. Nesse sentido, a investigação de Core, Holthausen e Larcker (1999), dentre outros, conclui que grandes pacotes de remuneração refletem fracos instrumentos de governança corporativa ao invés de bom desempenho organizacional.

Diante desse conflito de ideias em relação ao papel dos incentivos a executivos, sendo a remuneração tida tanto como ferramenta eficiente de alinhamento de interesses, como demonstração de fraca governança corporativa, Zalewska (2016) enfatiza que há uma expectativa natural de que a regulação seja uma forma de melhorar as falhas de mercado existentes, ainda que isso possa não acontecer.

\subsection{Teoria da Regulação e Remuneração}

A regulação é a maneira de limitar as ações de agentes econômicos e, dessa forma, proteger o bem- 
estar geral. Assim, a regulação é a incidência de qualquer ação do governo, no sentido de delimitar a liberdade de escolhas dos agentes econômicos, seja através de preços, quantidades, qualidade, segurança ou meio ambiente. Essas ações são definidas como externalidades, que interferem no bem-estar da sociedade ao criar custos adicionais (Prates, 2007).

Dessa forma, entende-se que as crises são cenários ideais para adoção de mecanismos regulatórios, em função da demanda social. Watts (1977) afirma que crises econômicas estimulam a regulação de mercado, embora questione a validade de explicações simplistas usadas pelos legisladores para justificar intervenções de remediação. Dessa forma, a relação entre crises econômicas e regulação é identificada, tendo em vista que, em período de crise, ficam expostas falhas de mercado, cuja existência já configura argumento suficiente para uma intervenção regulatória.

Embora, segundo Cardoso (2009), a regulação contábil seja uma resposta à regulação externa à Contabilidade, outros teóricos como Allee e Yohn (2009) argumentam que mesmo na ausência de regulação, ainda existirão incentivos privados para fornecer informações contábeis, e outros, como Akerlof (1970), Scott \& O'Brien (2019) e Campos (2008) sugerem que existem falhas no mercado da informação contábil, especificamente pela existência de externalidades da característica de bem público da informação contábil e da presença de assimetrias informacionais, as quais só podem ser corrigidas com a regulação.

O período de crise inserido nesse estudo é fator importante a ser observado nas análises e resultados que serão alcançados, principalmente em se tratando de instituições financeiras. Contudo, as falhas de mercado inerentes à remuneração dos executivos precisam ser definidas, como enfatiza a pesquisa de Edmans et al. (2017).

Portanto, se os acionistas (ou seus representantes do conselho) forem empoderados, informados e motivados, se os conselhos de administração estiverem agindo de acordo com o interesse dos acionistas e se a função objetiva dos acionistas estiver alinhada com o bem-estar social, não haverá necessidade de intervenção regulatória. Considerando que os acionistas suportam os custos diretos de compensações e de perdas com incentivos ineficientes, eles buscarão escolher contratos ótimos. Assim, a regulamentação só pode ser benéfica quando configurada a existência das falhas de mercado.

Por um lado, parece natural pensar que tanto os shareholders como os demais stakeholders, para o caso de instituições financeiras, devam possuir total acesso à informação dos valores recebidos pelos executivos. Porém, ao mesmo tempo, tal acesso traz consigo diversos efeitos, tendo em vista que as instituições financeiras possuem vínculos sociais que vão além dos interesses de shareholders (depositantes, outros bancos e demais partes interessadas), envolvendo nada menos que toda a economia de um país (Conyon et al. 2011). Mas ainda assim, entende-se que a abertura dessas informações é uma boa ferramenta de governança corporativa (Wei \& Yermack, 2011; Zalewska, 2016).

Por outro lado, as particularidades de cada país, que envolvem características peculiares quanto à economia e política, apontam diferenças entre a fórmula de incentivos a executivos no Brasil e demais países. Para o Brasil, Ferreira (2012) identificou que a remuneração de executivos é basicamente fixada em remuneração fixa e sugere que o país é menos suscetível a fraudes relacionadas à ganhos extraordinários, do que aqueles países que possuem remuneração baseada em remuneração variável, como é o caso de vários outros países da América do Norte e da Europa. Dessa forma, as possíveis fraudes em resultados gerariam, na média, pouco impacto na remuneração dos executivos, que é formada principalmente por remuneração fixa.

Considerando o fato de que no setor bancário as instituições estão conectadas entre si, entende-se que, consequentemente, o fracasso de um banco pode afetar a estabilidade de todo o setor financeiro (Liu, Quiet, \& Roth, 2015). Além disso, os serviços dos bancos estão profundamente ligados com as atividades econômicas de seus países. Mesmo nas economias mais avançadas, onde os mercados de ações são mais desenvolvidos, os bancos são fornecedores fundamentais de financiamento de atividades econômicas e comerciais. Logo, as dificuldades do setor bancário se refletirão na economia.

Portanto, para as instituições financeiras, a regulação da remuneração de executivos pode exercer um papel ainda mais arriscado, tendo em vista os efeitos colaterais na economia local e até global que envolvem o setor. Assim, se a regulação traz consigo custos exacerbados que podem atingir 
terceiros, logo, deve-se então considerar, de forma peculiar, o setor financeiro, visando a proteção de todas as partes (Conyon et al. 2011; Zalewska, 2016).

Outro aspecto que deve ser enfatizado, tratado por Zalewska (2016), se refere ao fato de que o crescimento a longo prazo do setor bancário deve ser garantido, e, permitir aos acionistas vincular a remuneração dos executivos ao desempenho do mercado de ações não é um bom caminho a seguir. Este ponto é reforçado pela literatura ao fornecer evidências de que os acionistas são efetivos na promoção de seus próprios interesses, (Cuñat, Giné, \& Guadalupe, 2015; Stathopoulos \& Voulgaris, 2016; Correa \& Lel, 2016; lliev \& Vitanova, 2017;).

Nesse sentido, atualmente admite-se que a regulação da remuneração deve ter um caráter que ultrapassa fronteiras e que a tomada de riscos pelos bancos precisa ser controlada. Porém, ainda não está claro se todas as mudanças impostas às práticas de remuneração são potencialmente positivas.

As dificuldades em encontrar a amplitude e profundidade da intervenção regulatória a nível internacional não devem ser ignoradas. Conyon et al. (2011) enfatiza que uma forte governança corporativa pode contribuir muito mais do que a regulação governamental nas práticas de remuneração de executivos. Além disso, Zalewska (2016) pontua a importância de se reconhecer que a intervenção reguladora exige o desenvolvimento de novas métricas de boas práticas de governança nas empresas.

Hitz e Müller-Bloch (2015) analisaram as reações do mercado de ações alemão frente à regulação da remuneração de executivos. Por meio da metodologia de estudo de eventos, foram encontradas evidências de uma reação média negativa do mercado à regulamentação. Além disso, as análises multivariadas mostraram que nas empresas mais afetadas, os executivos recebiam alta remuneração anormal.

Larcker, Ormazabal e Taylor (2011) analisaram a reação do mercado americano às ações legislativas e regulatórias relativas à governança corporativa. Por meio de estudo de eventos e simulação de Monte Carlo identificaram que os retornos anormais de eventos relacionados às regulamentações de governança corporativa estão, em média, diminuindo na remuneração do CEO. Em todos os testes, foram encontradas evidências robustas de reações negativas ao preço das ações para empresas cujas práticas de governança seriam afetadas pela regulação.

Assim, enfatiza-se a necessidade de que os reguladores olhem de maneira mais ampla e profunda para o setor bancário, além de participarem mais ativamente na determinação da remuneração como parte de uma agenda de monitoramento e restrição da tomada de riscos dos bancos. Edmans et al. (2017) enfatizam que a identificação da falha de mercado ainda deve ser uma condição necessária e anterior à regulação, pois destacará as áreas nas quais a abordagem regulatória provavelmente será efetiva ou contraproducente.

Dessa forma, o choque da regulação da remuneração dos executivos e a consequente percepção do mercado sobre os efeitos econômicos da regulação no preço das ações pode contribuir para um aprofundamento dessa discussão. A premissa subjacente é que qualquer regulação recebe vindicação somente se pode aumentar o bem-estar social, apesar de estudos, como de Zalewska (2016) e Hitz e Müller-Bloch (2015) para o mercado alemão, Murphy (2013) para a União Europeia e Larcker, Ormazabal e Taylor (2011) para os EUA, terem demonstrado reação negativa do mercado acionário à regulação.

\section{METODOLOGIA}

O presente estudo é classificado como descritivo e quantitativo, e para atingir o objetivo proposto que é o de compreender como os shareholders do setor bancário da B3 tiveram seus investimentos impactados em decorrência da publicação da IN CVM 480/2009, busca-se avaliar um contexto pré e pós regulação, a partir de uma série histórica cuja variável dependente é o valor da firma mensurado pelo valor de suas ações no mercado. A investigação segue a ideia proposta por Larcker, Ormazabal e Taylor (2011), Murphy (2013) e Hitz e Müller-Bloch (2015) que é verificar qual é o impacto da regulação da remuneração dos executivos no retorno das ações.

O modelo econométrico aplicado faz uso de Vetores Autorregressivos (VAR), baseado nos estudos de Sims (1980), o que enfatiza a originalidade e contribuição da pesquisa em buscar uma melhor compreensão e aprofundamento do tema, a partir de uma proposta diferenciada de investigação. O 
modelo obtido para desenvolvimento da pesquisa se apresenta adaptado para o mercado bancário, a partir da proposta metodológica de Conyon (1997).

\subsection{População e Amostra}

A amostra, inicialmente, era composta por 39 instituições financeiras de intermediação com registro ativo na CVM entre os anos de 2007 a 2016. Contudo, 5 instituições não possuem ações negociadas no mercado acionário e outras 9 não fizeram divulgação dos dados de remuneração dos seus executivos, restando 25 instituições com informações completas que foram utilizadas nesse trabalho.

Os dados da pesquisa foram coletados em 2018 a partir da base de dados Economática ${ }^{\circledR}$ - informações de retorno trimestral das ações; do sítio eletrônico da CVM (utilizando-se o software Empresas. Net para acessar o Formulário de Referência das empresas) e da Bolsa de Valores de São Paulo (BOVESPA), atualmente denominada B3 (Brasil, Bolsa, Balcão) para as informações relativas à remuneração dos executivos.
O retorno das ações foi calculado com base nos preços de retornos trimestrais por instituição. Foram calculadas, ainda, as médias por trimestre, sem considerar o tipo de ação (Ordinária ou Preferencial), assim como a identificação de cada instituição. Portanto, considerou-se o retorno médio trimestral das instituições, totalizando dez observações.

Os dados de remuneração média foram calculados por empresa e por ano, com base nas informações de remuneração da diretoria estatutária e quantidade de membros. Para cálculo da taxa de crescimento da remuneração média, os dados foram deflacionados pelo Índice Geral de Preços do Mercado (IGPM), ano base 2007.

\subsection{Escolha do Modelo Econométrico}

Parte-se de um modelo ARMA $(p, q)$ Autorregressivo com Média Móvel de ordens $p$ e $q$, tendo em vista que o valor das ações no tempo $t$ depende de seu valor nos períodos anteriores, sem desprezar os eventuais choques aleatórios (Gujarati \& Porter, 2011).

$$
Y_{t}=\alpha_{0}+\sum_{i=1}^{p} \alpha_{i} Y_{t-i}+\varepsilon_{t}+\sum_{i=1}^{q} \beta_{i} \varepsilon_{t-i}
$$

Onde, $p$ e q podem ser determinados através das funções de autocorrelação e autocorrelação parcial. Ressalta-se que este modelo será usado concomitante a um modelo de variável qualitativa que buscará avaliar mudança estrutural com a adoção do normativo.
O software Stata $^{\circledR}$ foi utilizado para testar diferentes modelos autorregressivos em função da existência de variáveis defasadas, sendo que aquele que demonstrou melhor ajuste tanto pelo critério Akaike (AIC) como pelo Schwarz (BIC) foi o modelo ARMA $(2,1)$. Os modelos testados estão descritos na Tabela 1.

Tabela 1 - Resultados dos testes Akaike e Schwartz

\begin{tabular}{c|c|c}
\hline Modelo & AIC & BIC \\
\hline ARMA(1,0) & 318.181 & 324.936 \\
\hline ARMA(1,1) & 320.056 & 328.501 \\
\hline ARMA $(2,0)$ & 319.796 & 328.240 \\
\hline ARMA(2,1) & 313.287 & 323.420 \\
\hline ARMA(2,2) & 321.115 & 332.937 \\
\hline
\end{tabular}

Fonte: elaborado pelos autores (2017). 
Para testar a estacionariedade da série (Figura 1), foi aplicado o teste de raiz unitária de Dickey-Fuller Aumentado (DFA) e de Kwiatkowski-Phillips-Schmidt-
Shin (KPSS), para dar mais robustez ao resultado, conforme indicado por Malbouisson e Tiryaki (2017).

Figura 1 - Retorno das ações (em \%) de 2007 a 2016, trimestralmente.

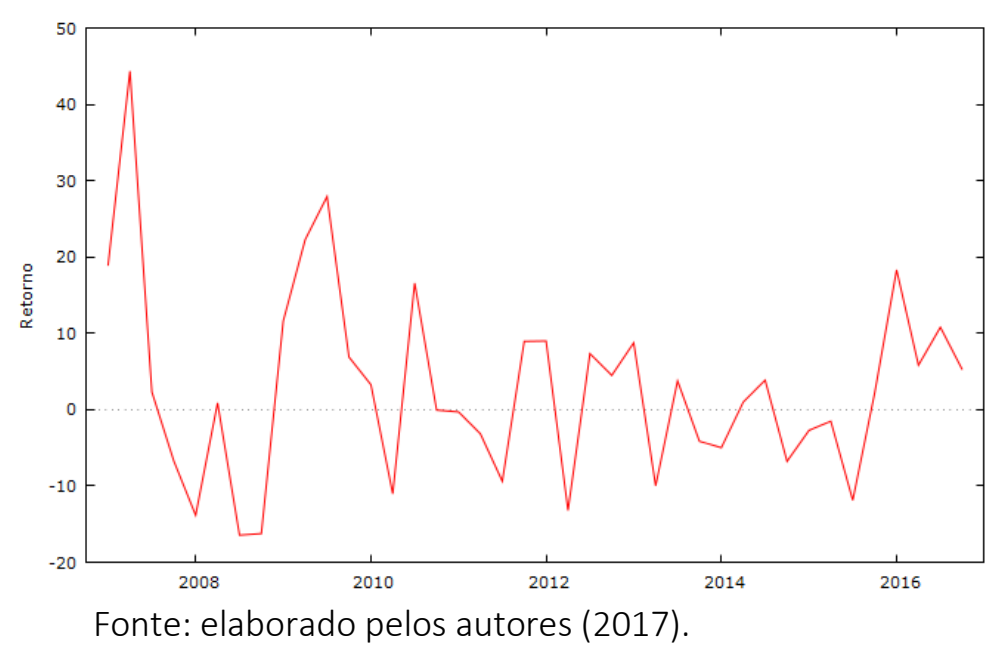

No teste DFA, os resultados mostram que a série é estacionária, favorável à hipótese alternativa, no nível (com $p$-value de 0,0036) estatisticamente significante a $1 \%$. Da mesma forma, no teste aplicado na primeira diferença (variação), a série foi considerada estacionária (com p-value 0,0305), apresentando significância estatística ao nível de 5\%.

O teste KPSS confirmou os resultados do teste DFA, mostrando que a série é estacionária, favorável à hipótese nula, no nível (com $p$-value de 0,0491) estatisticamente significante a $5 \%$. E da mesma forma, no teste KPSS aplicado na primeira diferença (variação), a série foi considerada estacionária (com p-value 0,0606), apresentando significância estatística ao nível de 10\%. Assim, viabiliza-se diretamente o teste de causalidade entre as variáveis, sem necessidade de ajustes.

\section{ANÁLISE E DISCUSSÃO DOS RESULTADOS}

Nesta seção, a análise e discussão dos resultados ocorre de forma subdividida, por meio da análise descritiva, resultados da aplicação do modelo econométrico com dados de retorno trimestral e análise de robustez por meio da metodologia de estudo de eventos com dados diários.

\subsection{Análise Descritiva}

A descrição dos dados de remuneração de executivos das empresas da amostra, possibilita uma melhor visualização da evolução da média de remuneração da diretoria estatutária ao longo dos anos de análise.

As informações relativas à remuneração total paga, em milhões de Reais (valores absolutos), pelos bancos analisados neste estudo estão descritas na Tabela 2, a qual traz ainda um intervalo de confiança para esta variável.

Nota-se que o ano de 2016 apresenta maior média de remuneração de executivos (R\$ 2,434 milhões) e desvio padrão (R\$ 2,749 milhões), representando uma variabilidade de $112 \%$, aproximadamente. Os anos de 2007 e 2008 apresentam valores inferiores em relação aos anos subsequentes, o que pode estar associado ao fato de a deliberação legal ter acontecido somente em dezembro de 2009, e que mesmo sendo retroativa ao ano de 2007, nem todas as instituições fizeram a divulgação da remuneração de seus executivos nesses períodos. Assim, das 25 empresas da amostra, 12 não divulgaram dados de 2007 e 9 não divulgaram dados de 2008. 
Tabela 2 - Estatística descritiva dos valores absolutos de remuneração dos executivos das instituições financeiras no período de 2007 a 2016 (em milhões de reais):

\begin{tabular}{c|c|c|c|c|c|c|c|c|c|c}
\hline $\begin{array}{c}\text { Estatística } \\
\text { descritiva }\end{array}$ & 2007 & 2008 & 2009 & 2010 & 2011 & 2012 & 2013 & 2014 & 2015 & 2016 \\
\hline Média & 0,319 & 0,604 & 1,107 & 1,461 & 1,537 & 1,859 & 2,156 & 2,116 & 2,194 & 2,434 \\
\hline Erro padrão & 0,215 & 0,481 & 0,689 & 0,809 & 0,780 & 0,954 & 1,302 & 1,268 & 1,243 & 1,135 \\
\hline Mediana & 0,022 & 0,231 & 0,633 & 0,718 & 0,682 & 1,086 & 1,160 & 1,166 & 1,077 & 1,691 \\
\hline Desvio padrão & 0,520 & 1,166 & 1,670 & 1,959 & 1,890 & 2,312 & 3,155 & 3,072 & 3,010 & 2,749 \\
\hline Intervalo & 1,767 & 5,486 & 7,912 & 8,135 & 7,413 & 9,011 & 13,312 & 15,25 & 14,526 & 12,400 \\
\hline Mínimo & 0,000 & 0,000 & 0,012 & 0,015 & 0,043 & 0,043 & 0,012 & 0,01 & 0,014 & 0,100 \\
\hline Máximo & 1,767 & 5,486 & 7,924 & 8,151 & 7,456 & 9,053 & 13,324 & 15,26 & 14,540 & 12,500 \\
\hline Intervalo de confiança \\
\hline Limite inferior & 0,104 & 0,123 & 0,417 & 0,652 & 0,757 & 0,905 & 0,853 & 0,848 & 0,951 & 1,299 \\
\hline Limite superior & 0,534 & 1,086 & 1,796 & 2,270 & 2,318 & 2,813 & 3,458 & 3,385 & 3,436 & 3,569 \\
\hline
\end{tabular}

Fonte: elaborado pelos autores (2017).

Percebe-se que a média de remuneração em 2009 aumentou $83 \%$ comparativamente com a que foi divulgada em 2008. Assim, a média de remuneração dos executivos apresenta tendência ascendente ao longo dos períodos analisados, como apresentado na Figura 2 e revela não haver sofrido alteração decorrente da regulação ocorrida em 2009.

Figura 2 - Remuneração média real dos executivos (em milhões de reais) de 2007 a 2016

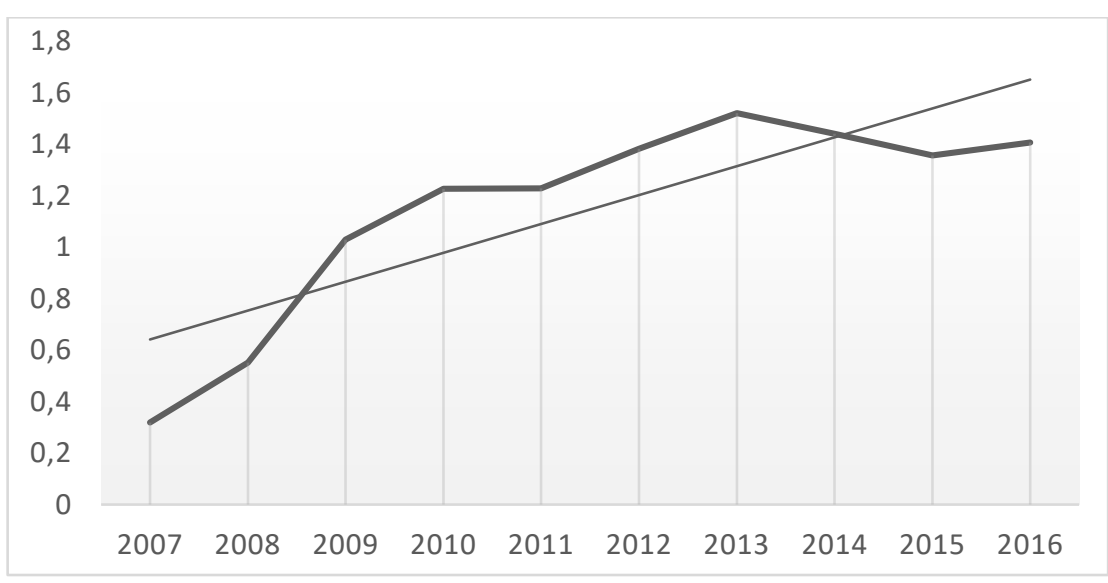

Fonte: elaborado pelos autores (2017).

Contudo, na Figura 3 é possível identificar que a taxa de crescimento da remuneração média, calculada com base nos dados de remuneração deflacionados, apresentou tendência de redução a partir de 2009, ano que está compreendido como auge da crise financeira e da promulgação da IN CVM $480 / 2009$. 
Figura 3 - Taxa de crescimento (em \%) da Remuneração média dos executivos entre 2007 e 2016.

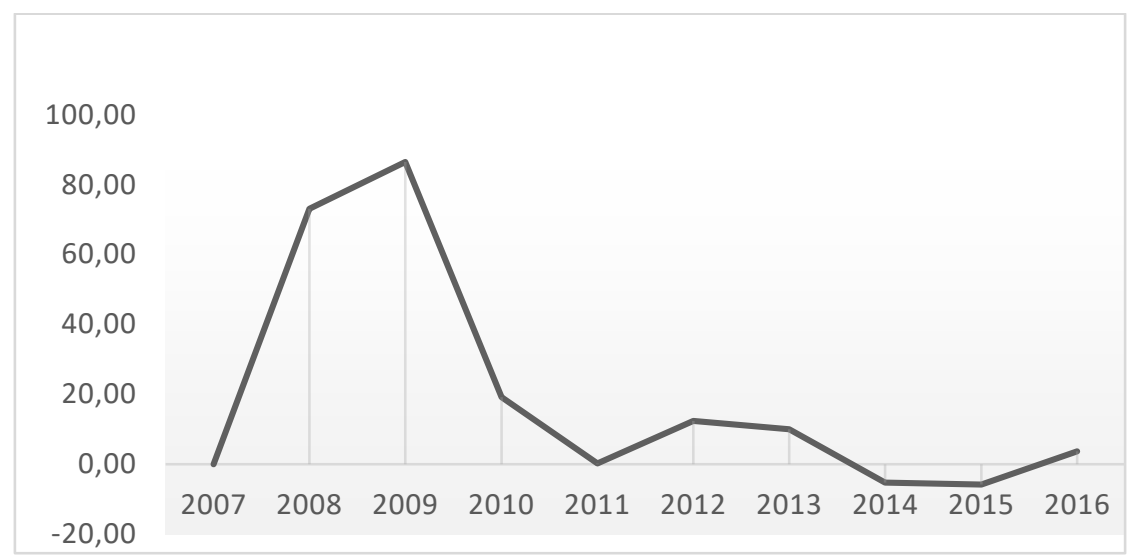

Fonte: elaborado pelos autores (2017).

Percebe-se, então, que a taxa real de crescimento da remuneração média sofreu queda de $78 \%$ em 2010. Houve aumento de $18 \%$ em 2009 comparativamente a 2008. Considerando-se que a regulação só aconteceu em dezembro de 2009, verifica-se o impacto real da regulação a partir de 2010, com queda em 2011, e alcançando taxas negativas nos anos de 2014 e 2015 como consequência da crise econômica brasileira que abrange o período de 2011 a 2014.

\subsection{Modelo Econométrico}

O modelo econométrico agrega ao modelo ARMA $(2,1)$ uma variável dummy, $D_{i}$ que assume valor 0 para períodos de remuneração anteriores ao normativo e 1 para remunerações em períodos posteriores, de modo que se pode escrever:

$$
Y_{t}=\alpha_{o}+\alpha_{1} Y_{t-1}+\alpha_{2} Y_{t-2}+\alpha_{3} D_{i}+\varepsilon_{t}+\beta_{1} \varepsilon_{t-1}
$$

A partir do modelo escolhido, ARMA (2,1), tem-se os resultados econométricos como demonstrado na Tabela 3.

Tabela 3 - Resultados da equação de regressão

\begin{tabular}{|c|c|c|c|c|c|}
\hline \multirow[b]{2}{*}{ Coeficiente } & \multirow[b]{2}{*}{ Erro Padrão } & \multirow[b]{2}{*}{ Z } & \multirow[b]{2}{*}{ Valor $\mathrm{P}$} & \multicolumn{2}{|c|}{ Intervalo de Confiança } \\
\hline & & & & Limite inferior & Limite superior \\
\hline \multicolumn{6}{|l|}{ Retorno } \\
\hline$D-4,35$ & 1,973141 & $-2,21$ & 0,027 & $-8,221532$ & $-8,221532$ \\
\hline _cons 5.12 & 1,561942 & 3,28 & 0,001 & 2,058765 & 8,181466 \\
\hline \multicolumn{6}{|l|}{ ARMA } \\
\hline$A R L 11,050602$ & 0,1830178 & 5,74 & 0,000 & 0,6918934 & 1,40931 \\
\hline$A R L 2-0,4376754$ & 0,138265 & $-3,17$ & 0,002 & -0.7086699 & $-0,166681$ \\
\hline MA L1 -1,000003 & 3505,462 & $-0,00$ & 1,000 & $-6871,58$ & 6869,58 \\
\hline /Sigma10.06729 & 17645,54 & 0,00 & 0,500 & 0 & 34594,68 \\
\hline
\end{tabular}

Fonte: Elaborado pelos autores (2017)

O modelo se mostrou estatisticamente significativo ao nível de 5\%. A diferença de médias captada pelo coeficiente nos períodos de 2007 a 2009 e 2010 a 2016 foi -4,35, o que confirma a ocorrência de mudança estrutural no retorno das ações no período posterior à regulação. Portanto, o impacto negativo no retorno das ações, está alinhado com os achados de Larcker, Ormazabal e Taylor (2011), Murphy (2013) e Hitz e Müller-Bloch (2015), que também demonstraram reação negativa à regulação utilizando os mesmos argumentos. A despeito da remuneração dos executivos em si não ter 
apresentado modificações em sua trajetória ascendente ao longo do tempo, os dados sugerem queda na taxa de crescimento real da remuneração média, o que pode significar impactos advindos da regulação em 2009.

A quebra estrutural apresentada neste estudo a partir da regulação, pode ser entendida como uma proxy na precificação dos ativos pelo mercado, o que pode representar supervalorização desses ativos em períodos anteriores à mesma, comprovando a existência do conflito de agência dentro da organização. Isso pode indicar que, para algumas empresas como os bancos, os participantes do mercado consideraram a regulação proposta potencialmente capaz de abalar os contratos de compensação e promover alinhamento de interesses dentro das organizações, o que corrobora os achados de Hitz e Müller-Bloch (2015).

Por um lado, não há qualquer mudança importante em sua estrutura em função da simples ordenança de que se revelasse a respectiva remuneração. Por outro lado, essa mudança no olhar dos acionistas sobre o setor financeiro foi captada através dos preços das ações das empresas, que sofreram desvalorização significativa, na série pósregulação. Assim, pode-se dizer que a regulação tem impacto relevante no nível de remuneração no Brasil, seguindo o mesmo efeito da regulação para o mercado americano, porém, enfatiza-se que este último teve aumento superior ao encontrado no presente estudo.

De acordo com Larcker, Ormazabal e Taylor (2011), no mercado americano estes efeitos podem ser entendidos como tentativa de compensação de possíveis impactos que reduziriam a motivação dos seus administradores. A redução da taxa de crescimento do nível de remuneração dos executivos de empresas listadas pode ser em decorrência do alto nível que o salário fixo representa no nível total de remuneração, conforme identificado por Anjos (2016). Sendo assim, a regulação da divulgação estaria gerando novas práticas de compensação de executivos, vinculando o total pago ao desempenho da organização, o que reduziu a taxa de crescimento existente no período anterior à IN CVM 480/2009.

Além disso, a redução do valor das ações das firmas pesquisadas permite inferir que os resultados decorrentes da regulação não geraram criação de valor para os acionistas. Logo, pode-se verificar que a redução da motivação dos gestores induziu a uma perda de utilidade para os investidores, o que deve ser ajustado no longo prazo quando o mercado conseguir se adaptar ao novo padrão de remuneração dos gestores, e sua divulgação, que compõem as diretorias estatutárias das firmas listadas na B3.

\subsection{Teste de Robustez - Estudo de Eventos}

De forma complementar à análise anteriormente realizada, optou-se em analisar também os dados diários das cotações das ações, por meio da metodologia de estudo de eventos, em que o evento é a divulgação da regulação (IN480) em 7 de dezembro de 2009. A janela do evento foi estabelecida considerando três dias antes e três dias depois do evento, conforme utilizado por Hitz e Müller-Bloch (2015). Definiu-se essa janela com o intuito de evitar a possibilidade de englobar outros eventos que pudessem enviesar os resultados, buscando assim, captar as anormalidades nos preços relacionadas à divulgação da regulação. A janela de estimação abrange o período de 10 dias para cálculo do retorno normal das ações.

Foram calculados os retornos normais na forma logarítmica para estabelecimento do padrão de normalidade e para a identificação das anormalidades dos retornos dos títulos em análise. Por meio desse padrão, estimaram-se os retornos esperados dos títulos, caso o evento (divulgação da IN480) não ocorresse. Por meio da diferença entre o retorno fornecido pelo modelo e o retorno real observado no período de análise, foi possível identificar indícios de que o evento tenha influenciado o comportamento dos retornos das ações (Takamatsu, Lamounier \& Colauto, 2008).

Como metodologia para cálculo do retorno anormal, foi estimada uma regressão por meio do método dos mínimos quadrados ordinários para os dados do período da janela de estimação para as 25 instituições (período de 6 dias anteriores ao evento), a partir de um modelo ajustado ao risco e ao mercado e que totalizou 175 observações. Dada a sua representatividade para o mercado, tomou-se como variável explicativa para o retorno dos títulos, os retornos do Ibovespa (Takamatsu, Lamounier \& Colauto, 2008). O resultado apresentou significância estatística ao nível de 5\%.

O Modelo de Mercado utilizado assume que o retorno dos ativos é uma variável dependente, 
determinada pelo retorno do Mercado e pelo risco do próprio título, o qual foi escolhido por ser um modelo já consolidado (Watts \& Zimmerman, 1986). Dessa forma, as etapas de cálculo ocorreram por meio de 5 equações a saber: Cálculo do retorno da ação e do mercado (equações 2 e 3), o retorno normal esperado (equação 4), o retorno anormal (equação 5) e o retorno anormal cumulativo (equação 6), conforme estudos de Brown e Warner (1985).

\begin{tabular}{c|r|} 
Retorno $_{i t}=\ln \frac{P_{t+1}}{P_{t}}$ & (2) \\
\hline RetMerc $_{i t}=\ln \frac{\text { Ibov }_{t+1}}{\text { Ibov }_{t}}$ & (3) \\
\hline $\operatorname{Resp}_{i t}=\beta_{0}+\beta_{1} \cdot R M_{i t}+\varepsilon$ & (4) \\
\hline$R A_{i t}=R_{i t}-R N_{i t}$ & (5) \\
\hline$C A R_{i t}=\sum_{t=1}^{n} R A_{i t}$ & (6)
\end{tabular}

Os retornos anormais (RA) das ações das empresas analisadas, foram calculados para 22 instituições que apresentavam dados disponíveis das cotações diárias. A Tabela 4 apresenta a estatística descritiva desses retornos.

Tabela 4 - Estatística Descritiva do Retorno Anormal Médio na janela do evento

\begin{tabular}{|c|c|c|c|c|c|}
\hline $\begin{array}{l}\text { Estatística } \\
\text { descritiva }\end{array}$ & 0 & 1 & 2 & 3 & $\begin{array}{l}\text { CAR } \\
(0,3)\end{array}$ \\
\hline Média & $\begin{array}{c}0.00186 \\
4\end{array}$ & $\begin{array}{c}- \\
0.00041\end{array}$ & $\begin{array}{c}- \\
0.00296\end{array}$ & -0.003048 & $-0.5 \%$ \\
\hline Mediana & -0.0064 & -0.0036 & -0.0066 & -0.0119 & $-2.9 \%$ \\
\hline $\begin{array}{l}\text { Desvio } \\
\text { padrão }\end{array}$ & 0.02342 & 0.02467 & $\begin{array}{c}0.02485 \\
8 \\
\end{array}$ & 0.03573 & $10.9 \%$ \\
\hline Mínimo & -0.0489 & -0.0726 & -0.0756 & -0.0989 & $0.0 \%$ \\
\hline Máximo & 0.029 & 0.048 & 0.03 & 0.044 & $15.1 \%$ \\
\hline
\end{tabular}

Fonte: Elaborado pelos autores (2021).

Por meio da Tabela 4 pode-se observar que o retorno anormal médio acumulado considerando até três dias após a data da divulgação da regulação foi de $-0.5 \%$, mostrando-se negativo no dia da divulgação e nos três dias seguintes ao evento. A mediana, da mesma forma, apresentou-se negativa nos mesmos dias, sendo o CAR igual a -2.9\%. A Figura 3 apresenta um comparativo entre os retornos médios esperados, os retornos observados (equação 4) e retornos anormais acumulados (equação 6). Os retornos esperados apresentam-se positivos ao longo da janela do evento. Observa-se grande variação dos retornos observados e as quedas no retorno anormal acumulado.

A simples observação do comportamento dos preços e dos retornos das ações, denota queda no nível geral no dia do evento e nos três dias subsequentes à regulação conforme apresenta a Figura 4. Para testar a real significância dessa queda em relação ao comportamento apresentado antes do evento, analisou-se a diferença das medianas dos retornos nos 3 dias antes e depois do evento em relação ao Retorno Anormal Acumulado (CAR). 
Figura 4 - Comparativo entre retornos esperado e retorno anormal e retorno anormal acumulado na janela do evento

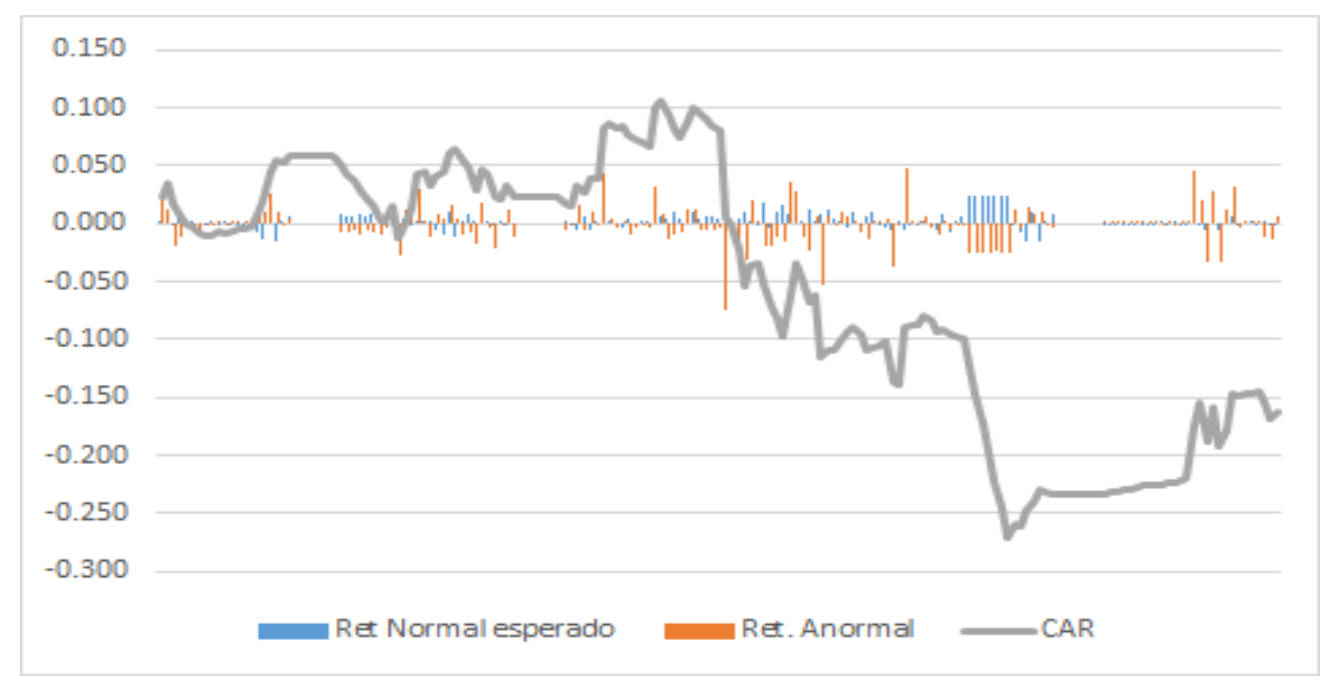

Fonte: elaborado pelos autores (2021).

Aplicou-se o teste Doornik-Hansen para verificar se a série de retorno anormal acumulado possuía distribuição normal. O resultado do teste foi significante a $5 \%$ e, portanto, não há normalidade na distribuição. Por meio do teste não paramétrico de Wilcoxon Mann-Whitney, analisou-se se houve indícios de que o evento Regulação tenha provocado reação negativa nos preços das ações. Portanto, a hipótese nula é de que não haveria diferença estatisticamente significativa entre os dias antes e depois da regulação (evento) e, portanto, esse tipo de evento (regulação) não teria influência na percepção dos investidores quanto à instituição em questão.

Tabela 5 - Resultado do Teste Mann-Whitney

\begin{tabular}{c|c|c}
\hline $\begin{array}{c}\text { Estatística de } \\
\text { Teste }\end{array}$ & $\begin{array}{c}\boldsymbol{H}_{\mathbf{0}}: \text { CAR (Dreg=0) } \\
\text { CAR(Dreg=1) }\end{array}$ & $\begin{array}{c}\boldsymbol{H}_{\mathbf{0}}: \text { CAR (Dreg=0) } \\
\text { CAR(Dreg=1) }\end{array}$ \\
\hline $\begin{array}{c}\text { U de Mann- } \\
\text { Whitney }\end{array}$ & 109843,60 & - \\
\hline$Z$ & 3,145 & - \\
\hline Prob $>|z|$ & 0,0017 & 0,639 \\
\hline
\end{tabular}

Dados da pesquisa (2021)

A Tabela 5 apresenta o resultado do teste que apresentou Prob $>|z|=0.0017$, constatando haver diferenças significativas ao nível de $5 \%$ e, portanto, implicando na rejeição da hipótese nula do teste e revelando que o mercado reagiu negativamente à regulação nos dias posteriores ao evento (dia zero) conforme mostra a Tabela 4.

\section{CONSIDERAÇÕES FINAIS}

O período analisado neste artigo envolve uma série de intempéries econômicas que atingiram a economia mundial, e principalmente o setor financeiro das economias desenvolvidas e em desenvolvimento. Este estudo se propôs a identificar o impacto da variação nos valores das ações das instituições financeiras listadas na B3 decorrente da mudança regulatória que exigia das empresas que divulgassem os salários de seus executivos, copiando o modelo internacional, no intuito de aumentar a transparência e evitar o comportamento oportunista dos agentes. Tais agentes, por estarem com suas remunerações vinculadas ao desempenho de curto prazo, poderiam utilizar subterfúgios para obter lucros extraordinários que comprometeriam a saúde de suas instituições e do próprio sistema financeiro.

Os resultados encontrados, utilizando vetores autorregressivos, nos quais os dados dependem das 
variáveis passadas, foram os esperados e também foram confirmados pelo estudo de eventos. Encontrou-se uma mudança estrutural significativa para o valor das ações, mostrando um decréscimo nesses preços após a regulação. O que surpreende para o cenário analisado é que apesar da exigência de publicação das fórmulas de remuneração desses executivos, a trajetória de ascensão dos incentivos, na média real, não sofreu grandes alterações, mostrando um descolamento da literatura internacional, em função de que esse fator foi exaustivamente apontado como preponderante para estimular a "criatividade financeira" dos agentes.

Todavia, os resultados encontrados mostram que houve queda na taxa de crescimento da média da remuneração real a partir de 2009. O impacto negativo advindo da regulação foi captado pelo modelo no mês seguinte à publicação da IN CVM 480/2009. Esse resultado foi reforçado com o estudo de eventos, que considerou as cotações diárias das ações dentro da janela de estimação utilizada. Portanto, os resultados apontam indícios de que os participantes do mercado enxergam a regulação proposta como potencialmente capaz de modificar os contratos de compensação e promover alinhamento de interesses dentro do setor, corroborando os achados de Hitz e Müller-Bloch (2015).

A influência da crise foi decisiva para a regulação da remuneração dos executivos e pode ser um indicativo de que há uma correlação com as decisões de investimentos dos acionistas. A queda da taxa de crescimento da remuneração sugere a manifestação de um conflito de agência e que, a partir da regulação, houve a incorporação das informações pelo mercado nos períodos posteriores. Esses fatores possivelmente contribuíram de forma conjunta para o impacto negativo no retorno das ações.

Este estudo traz contribuições para a literatura no sentido de que estimula o debate acerca das especificidades do setor bancário brasileiro sobre o desenvolvimento de mecanismos de governança corporativa voltados ao setor, como forma de mitigar a tomada de riscos que tendem a comprometer toda a economia do país. Os resultados também são importantes aos reguladores, na medida em que sugerem que a regulação foi benéfica na redução do conflito de interesses entre agente e principal.

Os resultados se restringem às instituições financeiras analisadas, não sendo passíveis de generalização. Ressalta-se, no entanto, que o método empregado pode ser replicado em contextos diferentes, para fins confirmatórios ou comparativos. Dentre as limitações do estudo destacam-se a pouca disponibilidade de dados de remuneração dos executivos, o que restringiu o tamanho da amostra, assim como a incoerência de alguns dados divulgados nos Formulários de Referência, devido à recente obrigatoriedade da divulgação. Considera-se que essas dificuldades se deram em função do processo de adaptação às exigências regulatórias.

A pesquisa teve como horizonte de abrangência a discussão do conflito de agência nas instituições financeiras, em um contexto que contemplou empresas brasileiras e internacionais, entre agente e principal. Assim, não fez parte do escopo deste estudo abordar o reflexo da divulgação da remuneração dos executivos na relação entre acionistas controladores e minoritários, o qual é característico do cenário interno do Brasil. Tal aprofundamento pode ser objeto de futuras pesquisas para uma discussão mais voltada para o mercado brasileiro.

Sugere-se ainda como pesquisa futura a realização de estudos de eventos com o propósito de avaliar separadamente a reação do mercado frente à regulação da remuneração dos executivos com um número maior de instituições, e, por conseguinte, confirmar os resultados alcançados por este estudo.

\section{REFERÊNCIAS}

Aguiar, A. B., \& Pimentel, R. C. (2017). Remuneração de executivos e desempenho no mercado brasileiro: Relações contemporâneas e defasadas. Revista de Administração Contemporânea, 21(4), 545-568.

Akerlof, G. A. (1978). The market for "lemons": Quality uncertainty and the market mechanism. In: Uncertainty in Economics. 235-251.

Allee, K. D., \& Yohn, T. L. (2009). The demand for financial statements in an unregulated environment: An examination of the production and use of financial statements by privately held small businesses. The Accounting Review, 84(1), 1-25.

Anjos, L. C. M. (2016). Relações entre eficiência técnica das organizações e remuneração a executivos à luz dos impactos da motivação e sensibilidade da 
remuneração ao desempenho. (Tese de Doutorado). Universidade de Brasília, Universidade Federal da Paraíba, Universidade Federal do Rio Grande do Norte, João Pessoa, PB, Brasil.

Resolução 3.921, de 25 de novembro de 2010. Dispõe sobre a política de remuneração de administradores das instituições financeiras e demais instituições autorizadas a funcionar pelo Banco Central do Brasil. Recuperado de http://www.bcb.gov.br/pre/normativos/busca/norm ativo.asp?tipo=Res\&ano=2010\&numero $=3921$

Bebchuk, L. A., \& FRIED, J. M. (2003). Executive compensation as an agency problem. Journal of Economic Perspectives, 17(3), 71-92.

Brown, S. J., \& Warner, J. B. (1985). Using daily stock returns: The case of event studies. Journal of financial economics, 14(1), 3-31.

Campos, H. A. (2008). Falhas de mercado e falhas de governo: uma revisão da literatura sobre regulação econômica. Braz. J. Int'l L., 5, 281.

Cardoso, R. L., Saravia E., Tenório, F. G., \& Silva, M. A. (2009). Regulação da contabilidade: teorias e análise da Lei no 11.638/07. Revista de Administração Pública, 43(4), 773-799. Recuperado de http://bibliotecadigital.fgv.br/ojs/index.php/rap/arti cle/view/6710/5293

Instrução CVM n. 480, de 7 de dezembro de 2009 Dispõe sobre o registro de emissores de valores mobiliários admitidos à negociação em mercados regulamentados de valores mobiliários. Recuperado de

http://www.cvm.gov.br/legislacao/instrucoes/inst48 $\underline{0 . h t m l}$

Coase, R. H. (1937). The nature of the firm. Economica. 4(16), 386-405. Recuperado de https://onlinelibrary.wiley.com/doi/abs/10.1111/j.1 468-0335.1937.tb00002.x. Doi: https://doi.org/10.1111/j.14680335.1937.tb00002.x

Conyon, M. J. (1997). Corporate governance and executive compensation. International Journal of Industrial Organization, 15(4), 493-509.
Conyon, M. J. (2006). Executive compensation and incentives. Academy of Management Perspectives, 20(1), 25-44.

Conyon, M. J., Fernandes, N., Ferreira M. A., Matos, P. \& Murphy, K. J. (2011). The executive compensation controversy: A transatlantic analysis, Fondazione Rodolfo de Benedetti, 1-142. Recuperado de

https://www.researchgate.net/publication/5021021 6 The Executive Compensation Controversy A Tr ansatlantic Analysis

Correa, R., \& Lel, U. (2016). Say on pay laws, executive compensation, pay slice, and firm valuation around the world. Journal of Financial Economics, 122(3), 500-520.

Cuñat, V., Gine, M., \& Guadalupe, M. (2015). Say pays! Shareholder voice and firm performance. Review of Finance, 20(5), 1799-1834.

De Angelis, D., \& Grinstein, Y. (2014). Performance terms in CEO compensation contracts. Review of Finance, 19(2), 619-651.

Oliveira, L., \& Abrita, M. B. (2016). Assimetria de informação e mercado de trabalho: Uma análise teórico-empírica para a economia brasileira. In Abrita, M. B., Rondina Neto, A., Silva, P. F. J., \& Silva, W. G. (Org.). Economia brasileira: desafios macroeconômicos e regionais. Jundiai: Paco Editoral, (pp. 99-126).

Edmans, A., Gabaix, X., \& Jenter, D. (2017). Executive compensation: A survey of theory and evidence. National Bureau of Economic Research. Recuperado de https://www.nber.org/papers/w23596

Ferreira, L. O. G. (2012). Padrões e características da remuneração de executivos de empresas brasileiras de capital aberto. (Dissertação de mestrado) Universidade de Brasília, Universidade Federal da Paraíba, Universidade Federal do Rio Grande do Norte, Brasília, DF, Brasil.

Frydman, C., \& Jenter, D. (2010). CEO compensation. Annual Review of Financial Economics, 2, 75-102. 
Garay, U., González, M., Guzmán, A., \& Trujillo, M. A. (2013). Internet-based corporate disclosure and market value: evidence from Latin America. Emerging Markets Review, 17, 150-168. Recuperado de https://www.sciencedirect.com/science/article/abs/ pii/S1566014113000599?via\%3Dihub. Doi: https://doi.org/10.1016/i.ememar.2013.09.002

Gujarati, D. N., \& Porter, D. C. (2011). Econometria básica. (5a ed.). Porto Alegre: AMGH Editora.

Hitz, J-M., \& Müller-Bloch, S. (2015). Market reactions to the regulation of executive compensation. European Accounting Review, 24(4), 659-684.

Instituto Brasileiro de Governança Corporativa. (2015). Código das melhores práticas de governança corporativa. (5a ed.). Recuperado de http://www.org.br/index.php/publicacoes/codigodas-melhores-praticas

Iliev, P., \& Vitanova, S. (2017). The effect of the Say-on-Pay in the US. Management Science, forthcoming.

Jensen, M. C., \& Meckling, W. H. (1976). Theory of the firm: Managerial behavior, agency costs and ownership structure. Journal of financial economics, 3(4), 305-360.

Larcker, D. F., Ormazabal, G., \& Taylor, D. J. (2011). The market reaction to corporate governance regulation. Journal of financial economics, 101(2), 431-448.

Liu, Z., Quiet, S., \& Roth, B. (2015, June 1). Banking sector interconnectedness: what is it, how can we measure it and why does it matter? Bank of England Quarterly Bulletin. Recuperado de https://ssrn.com/abstract=2620602

Malbouisson, C., \& Tiryaki, G. (2017). Econometria na prática. Rio de Janeiro: Alta Books.

Merchant, K. A., \& Stede, W. A. V. D. (2017). Management control systems: performance measurement, evaluation and incentives. (4th ed.). Harlow, UK: Pearson Education.
Murcia, F. D-R., \& Machado, M. V. (2014). Impacto do nível de disclosure corporativo na liquidez das ações de companhias abertas no Brasil. Contabilidade Vista \& Revista, 24(3), 54-77.

Murphy, K. J. (1999). Executive compensation. Handbook of labor economics, 3, 2485-2563.

Murphy, K. J. (2013). Regulating banking bonuses in the European Union: A case study in unintended consequences. European Financial Management, 19(4), 631-657.

Prates, T., \& Serra, M. (2007). Os impactos da regulação ambiental na inovação: algumas considerações. Revista Economia \& Tecnologia, 3(1), 129-136. Recuperado de https://revistas.ufpr.br/ret/article/view/29506/1920 $\underline{1}$

Scott, W. R., \& O'Brien, P. (2019). Financial accounting theory. (8th ed.). Upper Saddle River, NJ: Pearson.

Shleifer, A., \& Vishny, R. W. (1997). A survey of corporate governance. The Journal of Finance, 52(2), p. 737-783.

Shah, S. Z. A., Javed, T., \& Abbas, M. (2009). Determinants of CEO compensation empirical evidence from Pakistani listed companies. International Research Journal of Finance and Economics, 32(1), 149-159.

Sims, C. A. (1980). Macroeconomics and reality. Econometrica, 48(3), 1-48. Recuperado em http://www.vcharite.univmrs.fr/PP/lubrano/cours/Sims Eco1980.pdf

Stathopoulos, K., \& Voulgaris, G. (2016). The Importance of Shareholder Activism: The Case of Sayon-Pay. Corporate Governance: An International Review, 24(3), 359-370.

Sunder, S. (2014). Teoria da contabilidade e do controle. São Paulo: Atlas. 
Takamatsu, R. T., Lamounier, W. M., \& Colauto, R. D. (2008). Impactos da divulgação de prejuízos nos retornos de ações de companhias participantes do Ibovespa. Revista Universo Contábil, 4(1), 46-63.

Ventura, A. F. A. (2013). Remuneração executiva, governança corporativa e desempenho: uma análise nas empresas listadas na BM\&FBovespa. (Dissertação de Mestrado). Universidade de Brasília, Universidade Federal da Paraíba, Universidade Federal do Rio Grande do Norte, João Pessoa, PB, Brasil.

Watts, R. L. (1977). Corporate financial statements, a product of the market and political processes. Australian journal of management, 2(1), 53-75.

Watts, R. L., \& Zimmerman, J. L. (1986). Positive accounting theory.

Wei, C., \& Yermack, D. (2011). Investor reactions to CEOs' inside debt incentives. The Review of Financial Studies, 24(11), 3813-3840.

Zalewska, A. (2016). A new look at regulating bankers' remuneration. Corporate Governance: An International Review, 24(3), 322-333.

\section{Sobre os autores:}

Juliana Costa Ribeiro Prates - Universidade Federal de Pernambuco - UFPE, Recife, PE (Brasil). Email: julianacrprates@gmail.com Orcid id: https://orcid.org/0000-0003-1289-3937

Wellington Silva Porto - Universidade Federal de Pernambuco - UFPE, Recife, PE (Brasil). Email: wsporto2009@gmail.com Orcid id: https://orcid.org/0000-0002-0289-9422

Maurício Assuero Lima de Freitas - Universidade Federal de Pernambuco - UFPE, Recife, PE (Brasil). Email: massuero@ig.com.br Orcid id: https://orcid.org/0000-0002-0437-3571

Luiz Carlos Maques dos Anjos - Universidade Federal de Pernambuco - UFPE, Recife, PE (Brasil). Email: luiz.cmanjos@ufpe.br Orcid id: https://orcid.org/0000-0002-7375-540X 


\title{
MARKET REACTIONS FACE OF THE EXECUTIVE PAYMENT REGULATION: AN INVESTIGATION ON THE NATIONAL AND INTERNATIONAL BANKING SECTOR LISTED IN [B] 3
}

\author{
Juliana Costa Ribeiro Prates, Wellington Silva Porto, Maurício Assuero Lima de Freitas, \\ Luiz Carlos Maques dos Anjos \\ Universidade Federal de Pernambuco - UFPE, Recife, Pernambuco, (Brasil)
}

\begin{tabular}{l} 
ARTICLE DETAILS \\
\hline Article history: \\
Received: 4 May 2020 \\
Accepted: 7 July 2021 \\
Available online September: 01 th 2021 \\
Double Blind Review System \\
Scientific Editor \\
Ilan Avrichir \\
\hline Keywords \\
Executive Compensation \\
Regulation \\
Structural Breakdow \\
VAR \\
Event Study
\end{tabular}

\begin{abstract}
Objective: To understand how B3's banking sector shareholders had their investments impacted in view of the introduction of the mandatory disclosure of executive compensation in Brazil, as a result of the publication of IN CVM $480 / 2009$
\end{abstract}

Method: In order to identify the structural breakage, it was conducted a comparison analysis of the conditional means, with the use of autoregressive vectors (VAR) to identify the structural break and the methodology for studying events.

Main results: The results show that there has been a structural drop in the average shareholder return as well as in the growth rate of the average remuneration of executives, with a negative impact in the period after the regulation. The model captured the negative impact in the month after the publication of IN CVM 480/2009 and also in the following 3 days after the regulation.

Relevance/Originality: The results are important to regulators and other market participants, as they indicate a change in the perception of market participants from regulation, showing that regulation can modify executive compensation contracts and thus promote the alignment of interests within the financial sector.

Theoretical/methodological contributions: The study contributes to the understanding of the effects of regulation on the executives's remuneration in Brazilian financial sector. It also brings contributions to the literature as it stimulates the debate about the specificities of the Brazilian banking sector on the development of corporate governance mechanisms aimed, as a way to mitigate the risk taking that tends to compromise the entire economy of the country. The results are also important to regulators, insofar as they suggest that regulation was beneficial in reducing the conflict of interest between agent and principal. In addition, the methodological contribution consists of using the VAR model (Self-Regressive Vectors) in parallel to the study of events, reinforcing the originality of the research and promoting a deeper understanding of the theme. 


\title{
REACCIONES DEL MERCADO ACCIONARIO FRENTE A LA REGULACIÓN DE LA REMUNERACIÓN EJECUTIVA: UNA INVESTIGACIÓN SOBRE EL SECTOR BANCARIO NACIONAL Y INTERNACIONAL EN [B]3
}

\author{
Juliana Costa Ribeiro Prates, Wellington Silva Porto, Maurício Assuero Lima de Freitas, \\ Luiz Carlos Maques dos Anjos \\ Universidade Federal de Pernambuco - UFPE, Recife, PE (Brasil)
}

\begin{tabular}{l} 
DETALLES DEL ARTÍCULO \\
\hline Historia del Artículo: \\
Recibido: 4 de Mayo de 2020 \\
Aceptado: 7 de Julio de 2021 \\
Disponible en línea: 01 de Septiembre 2021 \\
Double Blind Review System \\
Editor Científico \\
Ilan Avrichir \\
\hline
\end{tabular}

\section{Palabras-clave:}

Compensación Ejecutiva

Regulación

Ruptura estructural

VAR

Estudio de Eventos

\section{RESUMEN}

Objetivo: Comprender cómo los accionistas del sector bancario de B3 vieron impactadas sus inversiones en vista de la introducción de la divulgación obligatoria de compensación ejecutiva en Brasil, como resultado de la publicación de IN CVM 480/2009.

Método: Para el desarrollo de la investigación se realizó un análisis de la comparación de medias condicionales con el uso de vectores autorregresivos (VAR), para identificar la ruptura estructural y la metodología de estudio de eventos.

Resultados principales: Los resultados muestran que hubo una ruptura estructural en la rentabilidad media de la acción así como en la tasa de crecimiento de la remuneración media de los ejecutivos, con un impacto negativo en el período posterior a la regulación. El impacto negativo derivado de la regulación fue captado por el modelo en el mes siguiente a la publicación de la EN CVM 480/2009 y en los 3 días posteriores a la regulación.

Relevancia/Originalidad: Los resultados son importantes para los reguladores y otros participantes del mercado, ya que indican un cambio en la percepción de los participantes del mercado de la regulación, mostrando que la regulación puede modificar los contratos de compensación de ejecutivos y así promover la alineación de intereses dentro del sector financiero.

Contribuciones teóricas/metodológicas: El estudio contribuye a la comprensión de los efectos de la regulación sobre la remuneración de los ejecutivos en el sector financiero. Este estudio aporta contribuciones a la literatura porque estimula el debate sobre las especificidades del sector bancario sobre el desarrollo de mecanismos de gobierno corporativo dirigidos al sector, como una forma de mitigar la toma de riesgos que tiende a comprometer a toda la economía del país. Los resultados también son importantes para los reguladores, en la medida en que sugieren que la regulación fue beneficiosa para reducir el conflicto de intereses entre el agente y el principal. Además, el aporte metodológico consiste en utilizar el modelo VAR (Vectores Autorregresivos) en paralelo al estudio de eventos, reforzando la originalidad de la investigación y promoviendo una comprensión más profunda del tema.

\section{Como citar este artigo:}

Prates, J. C. R., Porto, W. S., Freitas, M. A. L. de, \& Anjos, L. C. M. dos. (2021). Reações do Mercado Acionário Frente à Regulação da Remuneração dos Executivos: Uma Investigação sobre o Setor Bancário Nacional e Internacional Listado na [B]3. Internext, 16(3), 252-270. https://doi.org/10.18568/internext.v16i3.609 